\title{
Incidence of subsequent fractures in the UK between 1990 and 2012 among individuals 50years or older
}

\author{
Citation for published version (APA):
}

van der Velde, R. Y., Wyers, C. E., Geusens, P. P. M. M., van den Bergh, J. P. W., de Vries, F., Cooper, C., van de Staa, T. P., \& Harvey, N. C. (2018). Incidence of subsequent fractures in the UK between 1990 and 2012 among individuals 50years or older. Osteoporosis International, 29(11), 2469-2475. https://doi.org/10.1007/s00198-018-4636-0

Document status and date:

Published: 01/11/2018

DOI:

10.1007/s00198-018-4636-0

Document Version:

Publisher's PDF, also known as Version of record

Document license:
Taverne

\section{Please check the document version of this publication:}

- A submitted manuscript is the version of the article upon submission and before peer-review. There can be important differences between the submitted version and the official published version of record.

People interested in the research are advised to contact the author for the final version of the publication, or visit the DOI to the publisher's website.

- The final author version and the galley proof are versions of the publication after peer review.

- The final published version features the final layout of the paper including the volume, issue and page numbers.

Link to publication

\footnotetext{
General rights rights.

- You may freely distribute the URL identifying the publication in the public portal. please follow below link for the End User Agreement:

www.umlib.nl/taverne-license

Take down policy

If you believe that this document breaches copyright please contact us at:

repository@maastrichtuniversity.nl

providing details and we will investigate your claim.
}

Copyright and moral rights for the publications made accessible in the public portal are retained by the authors and/or other copyright owners and it is a condition of accessing publications that users recognise and abide by the legal requirements associated with these

- Users may download and print one copy of any publication from the public portal for the purpose of private study or research.

- You may not further distribute the material or use it for any profit-making activity or commercial gain

If the publication is distributed under the terms of Article $25 \mathrm{fa}$ of the Dutch Copyright Act, indicated by the "Taverne" license above, 


\title{
Incidence of subsequent fractures in the UK between 1990 and 2012 among individuals 50 years or older
}

\author{
R. Y. van der Velde ${ }^{1,2}$. C. E. Wyers ${ }^{1,2}$ - P. P. M. M. Geusens ${ }^{3,4}$ - J. P. W. van den Bergh ${ }^{1,2,4}$ • F. de Vries ${ }^{5,6}$. \\ C. Cooper ${ }^{7,8,9}$ (D) T. P. van de Staa ${ }^{6,9,10} \cdot$ N. C. Harvey ${ }^{7,8}$
}

Received: 12 February 2018 / Accepted: 9 July 2018 / Published online: 20 July 2018

(C) International Osteoporosis Foundation and National Osteoporosis Foundation 2018

\begin{abstract}
Summary We studied the incidence of subsequent fractures in persons of 50+ years from 1990 to 2012 and the relative risk (RR) of subsequent fractures after an index femur/hip fracture, stratified per 5-year age band. Patients suffering a fracture have a high incidence of a subsequent fracture; the RR of subsequent fracture after a femur/hip fracture ranged from 2 to 7.

Introduction Recent information on the risk of subsequent fractures after a broad range of index fractures in the UK population is scarce. We therefore studied the rates of subsequent fractures of the femur/hip, humerus, radius/ulna, vertebrae, rib, or pelvis after fractures at one of these sites from 1990 to 2012 in 3,156,347 UK men and women aged 50 years or over.

Methods We undertook a retrospective observational study using the UK Clinical Practice Research Datalink (CPRD). The incidence of subsequent fractures at a specific site was calculated by dividing the observed number of fractures by the number of person-years (py) at risk. The relative risk (RR) of subsequent fractures after a femur/hip fracture, by 5-year age band, was calculated by dividing the incidence of a specific subsequent fracture type by the incidence of first fractures at the same site in the same age group.

Results The highest subsequent fracture incidence after a femur/hip fracture was for humerus fracture in men (59.5/10.000 py) and radius/ulna fracture in women (117.2/10.000 py). After an index fracture of the radius/ulna, humerus fracture in men (59.3/ $10.000 \mathrm{py})$ and femur/hip fracture in women ( 82.4 per $10.000 \mathrm{py})$ were most frequent. The RR of fractures after a femur/hip fracture ranged from 2 to 7 and were highest in men and younger age groups.

Conclusion Patients suffering a fracture have a high incidence of a subsequent fracture. Our findings demonstrate the importance of fracture prevention in patients with a history of a fracture by adequate medical diagnosis and treatment.
\end{abstract}

Keywords Epidemiology $\cdot$ Fracture incidence $\cdot$ Osteoporosis $\cdot$ Subsequent fractures

T. P. van de Staa and N. C. Harvey are joint senior author

Electronic supplementary material The online version of this article (https://doi.org/10.1007/s00198-018-4636-0) contains supplementary material, which is available to authorized users.

\section{Cooper}

cc@mrc.soton.ac.uk

1 Department of Internal Medicine, VieCuri Medical Centre, PO Box 1926, 5900 BX Venlo, The Netherlands

2 Department of Internal Medicine, NUTRIM School for Nutrition, Toxicology and Metabolism, Maastricht University Medical Centre (MUMC), PO Box 616, 6200 MD Maastricht, The Netherlands

3 Department of Internal Medicine, Subdivision Rheumatology, CAPHRI, Maastricht University Medical Centre (MUMC), PO Box 616, 6200 MD Maastricht, The Netherlands

4 Biomedical Research Centre, Hasselt University, Agoralaan gebouw D, 3590 Diepenbeek, Belgium
Department of Clinical Pharmacy \& Toxicology, Maastricht University Medical Centre+, Maastricht, The Netherlands

6 Department of Pharmacoepidemiology \& Clinical Pharmacology, Utrecht Institute for Pharmaceutical Sciences, Utrecht University, Utrecht, The Netherlands

7 MRC Lifecourse Epidemiology Unit, University of Southampton, Southampton, UK

8 NIHR Southampton Biomedical Research Centre, University of Southampton and University Hospital Southampton NHS Foundation Trust, Tremona Road, Southampton, UK

9 NIHR Oxford Biomedical Research Centre, University of Oxford, Oxford, UK

10 Health eResearch Centre, University of Manchester, Manchester, UK 


\section{Introduction}

The risk of an osteoporotic fracture can be significantly reduced by the initiation of appropriate medical treatment in those at high risk [1]. However, the identification of individuals in the general population at high risk of fracture is challenging. Although bone mineral density (BMD) is a powerful predictor of the risk of future fractures, there is little evidence that BMD-based population screening is cost-effective [2,3]. Furthermore, because densitometric osteoporosis identifies a small proportion of the population, and low BMD forms just one of several risk factors for fracture (for example falls), the majority of fragility fractures actually occur not in patients with osteoporosis but in those with osteopenia [4]. There is strong evidence that a history of a fragility fracture confers an increased risk of a subsequent fracture [5-9], and indeed, the UK SCOOP trial demonstrated that screening using 10-year fracture probability calculated with the FRAX algorithm (which includes prior fracture as an input variable) leads to a reduction in the risk of hip fracture and is cost-effective [3]. This increased risk is not limited to prior hip and spine fractures [5] and is to some extent independent of BMD [5]. Despite the development of pharmacological interventions with proven efficacy [1] and the publication of practice guidelines $[10,11]$, only a minority of patients with an incident fragility fracture actually receive appropriate treatment [12]. This treatment-gap may, at least partly, be explained by a lack of awareness of the importance of a prior fracture [13, 14]. It is critical to determine that the magnitude of subsequent fracture risk is important so that clinicians and patients might be better informed about the risk of a sustaining a further fracture and the potential benefit of treatments which could ameliorate this risk.

Although several studies [15-19] and meta-analyses [5, 6] on the risk of subsequent fractures have been published, recent information on the risk of subsequent fractures after a broad range of index fracture types in the UK population are scarce [20]. We therefore studied the rates of subsequent fractures at one of six sites (femur/hip, humerus, radius/ulna, vertebra, rib, or pelvis) after index fractures at one of the same sites from 1990 to 2012 in UK men and women aged 50 years or over, stratified by age.

\section{Methods}

\section{Data sources}

We conducted a retrospective observational study using data from the Clinical Practice Research Datalink (CPRD), formerly known as the General Practice Research Database $[21,22]$. In the universal health care system in the UK (the National Health Service, NHS), general practitioners (GPs) play a pivotal role, providing primary health care for $98 \%$ of the population and referring patients for specialist consultations or hospital admissions. The medical records of the GPs contain prospective information on demographics, prescriptions, and diagnoses made by GPs and diagnoses from specialist consultations, outpatient visits, and hospitalizations $[23,24]$. The CPRD covers over 11.3 million individuals from 674 practices in the UK. Around 4.4 million individuals are active (alive, currently registered) and meet quality criteria, accounting for approximately $6.9 \%$ of the UK population [25]. The cohort as a whole has been shown to be broadly representative of the UK population in terms of age, sex, and ethnicity when compared with the UK census in 2011 [25, 26]. Clinical data for each patient are captured and stored in CPRD using READ codes for disease or causes of morbidity or mortality, which are cross-referenced to the International Classification of Diseases 9th edition (ICD-9) [27]. The database contains information on both hospital admissions and hospital outpatient attendances, for example those at an Emergency Department. Information including date of attendance and diagnosis is passed from the hospital to the general practitioner, coded, and recorded in the database. Data quality assessments are performed at the practice level [24]. Independent validation studies have reported that the clinical data in the CPRD are in general of high quality, including reliable recording of fracture events [28-30]. This research was conducted in accordance with the principles of the Helsinki declaration, and the protocol for this study was approved by CPRD's Independent Scientific Advisory Committee. All data on patients were stored anonymously in CPRD, and therefore, informed consent was not required for this study.

\section{Study population}

The study population consisted of women and men of 50+ years, who were registered at a participating GP practice between 1990 and 2012. Fracture types were classified according to the ICD-9 classification including the following categories: clinical vertebra $(805,806)$, rib (807), pelvis (808), humerus (812), radius/ulna (813), and femur/hip $(820,821)$. For participants, the first fracture of the femur/hip, humerus, radius/ulna, vertebra, rib, or pelvis that occurred after the start of data collection was identified. From the date of this index fracture, the participants were followed until occurrence of a subsequent fracture of the femur/hip, humerus, radius/ulna, vertebrae, rib or pelvis, or censoring (death, withdrawal from the database, or the end of data collection), whichever came first. Subsequent fractures at the same site as the index fracture were excluded from follow-up because it is not possible within the CPRD to identify whether a GP consultation refers to a new or old fracture. 


\section{Statistical analysis}

Age- and sex-specific fracture incidence rates were calculated for all subsequent fracture types. Information on the dates of start and end of follow-up and the date of subsequent fracture were available for all patients in CPRD. However, the size of the database (including records of around 4.4 million individuals) prohibited the practical use of the exact person-time, so pragmatically, we counted the number of patients who were enrolled in CPRD at each midyear point (stratified by age and sex), thus providing the sum of follow-up.

We counted the number of patients who suffered a subsequent fracture at a specific site. The average fracture incidence was then calculated by dividing the sum of patients with a specific subsequent fracture by the sum of person-time follow-up for the whole period 1990-2012. We calculated the relative risk (RR) of a subsequent fracture of the humerus, vertebra, and radius/ulna after an index femur/hip fracture by 5 -year age band (the age at the time of diagnosis of the subsequent fracture) using data on the mean age- and sex-specific fracture incidence rates of a first fracture of the humerus, vertebra, and radius/ulna in the UK in persons 50 years or older for the period 1990 until 2012 from our previously published study [21]. The RR was calculated by dividing the incidence rate of a specific subsequent fracture type by the incidence rate of a first fracture at the same site. In order to investigate any possible secular trends in subsequent fracture risk, we calculated the mean incidences in the first 11 years of follow-up and the last 11 years separately, using hip/femur and radius/ulna as the index fractures. We then calculated the incidence rate ratio, 95\% confidence interval (CI), and $p$ value using Poisson regression. Analyses were performed using SAS 9.3 (SAS Institute Inc., Cary, North Carolina, USA) and Stata 13.1 (Statacorp, College Station, Texas, USA). The study was approved by the Independent Scientific Advisory Committee (ISAC) for Medicines and Healthcare products Regulatory Agency database research (ISAC approval 14_032).

\section{Results}

In total, we studied data of 3,156,347 persons: $1,457,446$ men, and 1,698,901 women. The average age was 61.5 (SD 12) years; in men, this was 60.5 years (SD 11.2), and in women 62.3 years (SD 12.7). The absolute number of each index fracture/ subsequent fracture combination, in both men and women, can be found in Online Supplementary Table 1A and $1 \mathrm{~B}$.

\section{Incidence of subsequent fractures}

A subsequent femur/hip fracture was most frequently observed after an index fracture of the pelvis (Tables 1 and 2).
The highest incidence of subsequent vertebral fracture was observed in both sexes after an index femur/hip fracture. As shown in Online Supplementary Fig. 1, the incidence of subsequent fracture after an index femur/hip fracture increased with age only for fractures of the pelvis in women of 70 years or older. After an index vertebral fracture, an increase in subsequent fracture incidence was seen in hip fractures in women above 60 years and in pelvic fractures in women above 65 years and men above 75 years (Online Supplementary Figs. 2 and 3).

\section{Age-specific incidence of subsequent fractures after an index fracture of the hip}

The incidence of a subsequent vertebral fracture after an index fracture of the femur/hip varied in men from 14.5 fractures per 10,000 py for the age class $50-54$ years to 56.1 fractures per 10,000 py for those aged 60-64 years (Table 3 ). In women, the corresponding incidence ranged from 16.0 for age 55-59 years to 56.1 for those aged 60-64 years. For subsequent fracture of the humerus after femur/hip fracture, the incidence varied from 44.5 for the age class $60-64$ years to 75.8 for those aged $55-59$ years in men and from 61.8 for the age class 60 69 years to 106.6 for those aged $50-54$ years in women.

\section{Relative risk for subsequent fractures}

The highest RRs after an index femur/hip fracture were in general found in the younger age classes, while the RRs in the oldest age classes were in general the lowest (Table 4). The $\mathrm{RR}$ of a subsequent vertebral fracture and fracture of the humerus was in general higher in men than in women. The RR of a subsequent vertebral fracture after an index fracture of the femur/hip varied in men from 1.8 for the age class $90+$ years to 17.5 for those aged 60-64 years (Table 4). In women, this RR ranged from 1.6 for the age class $90+$ to 11.5 for those aged 60-64 years. The RR of a subsequent fracture of the humerus after an index fracture of the femur/hip in men varied from 2.7 for the age class 85-89 years to 12.9 for those aged 55-59 years (Table 4). In women, this RR ranged from 2.2 for the age class $90+$ years to 14.2 for those aged $50-54$ years. There was no evidence of any statistically significant difference in incidence rates of fractures after an index hip/femur fracture or radius/ulna fracture comparing the second (20012012) with the first (1990-2012) half of the calendar period for men. However, for women, there was evidence of a secular increase in the risk of subsequent vertebral fracture after radius/ulna, a decrease in rib after hip/femur or radius/ulna index fractures, and a decrease in radius/ulna fractures after hip/ femur fracture comparing the latter with an earlier calendar period (Online Supplementary Table 2A and 2B). 
Table 1 Average incidence per 10,000 person-years of subsequent fracture from 1990 to 2012 in men aged $50+$ years

\begin{tabular}{lllllll}
\hline \multicolumn{7}{l}{ Subsequent fracture } \\
\cline { 2 - 6 } Index fracture & Hip/femur & Vertebra & Humerus & Radius/ulna & Pelvis & Rib \\
\hline Hip/femur & & 41.7 & 59.5 & 37.8 & 33.5 & 24.4 \\
Vertebra & 70.7 & & 44.0 & 25.9 & 18.8 & 47.3 \\
Humerus & 68.7 & 25.6 & & 71.3 & 9.1 & 20.7 \\
Radius/ulna & 38.5 & 3.5 & 59.3 & & 7.2 & 17.9 \\
Pelvis & 139.2 & 49.4 & 71.7 & 37.1 & & 38.2 \\
Rib & 32.7 & 30.3 & 24.4 & 27.7 & 7.0 & a \\
\hline
\end{tabular}

${ }^{a}$ The number of fractures was too few to calculate meaningful incidence rates

\section{Discussion}

In this retrospective, observational study, using data from the CPRD database, we have described the incidence of subsequent fractures after a first fracture of the femur/hip, humerus, radius/ulna, vertebra, rib, or pelvis in the UK in persons 50 years or older for the period 1990 to 2012, together with the RR of fractures of the humerus, radius/ulna, or vertebra after an index femur/hip fracture. We found that patients suffering a fracture in general have a high incidence of a subsequent fracture. The RR of a subsequent fracture after a femur/ hip fracture (compared with a first fracture at the same site) was highest in the younger age groups and in men, and in most subgroups ranged from 3 to 7 for subsequent vertebral fracture and fracture of the humerus, and from 2 to 5 for subsequent fractures of the radius/ulna.

In general, our results are consistent with, and extend, findings of meta-analyses and cohort studies published previously. In a study from the UK published in 2002 [15], using the same CPRD database, there was a 2- to 3-fold increase in the risk of subsequent fractures at different skeletal sites after an index femur/hip fracture. This lower increase in fracture risk can be explained by the fact that in this study, persons 20 years or older were included, while we studied patients of 50 years or older. In the study from 2002, the standardized incidence ratio (SIR) of a subsequent vertebral fracture or fracture of radius/ ulna after a femur/hip fracture was also determined in both men and women in the age groups $65-74,75-84$, and $85+$ years. In women, the SIR of fractures of the radius was lower than our RR in all three age groups, whereas the SIR of vertebral fractures was lower than the RR we found only in the age group 65-74 years, while in the other two age groups, the values were similar. In men in the age group $65-74$, the SIR for both vertebral fractures and fractures of radius/ulna was higher than the RR we found; in the other two age groups, the results overall were similar to our results. A secular trend in subsequent fractures was recently described in a study using the same CPRD database to determine the absolute risk of fragility fractures after an index femur/hip fracture [20]. In this study, the authors reported an increase in the risk of sustaining a major or any (non-hip) fracture after a femur/hip fracture, especially in the longer term with $32.5 \%$ of the patients sustaining a fracture after 5 years.

In line with the findings of van Staa et al. [15], our study suggests that the RR for subsequent fractures was generally higher in men then in women, which has also been observed in other studies [31]. We found that the RR of subsequent fractures was higher among younger persons compared with older individuals, and again, this is in keeping with the results from the UK study from 2002 [15]. These findings in relation to men and younger ages probably reflect that sustaining a fracture in these situations is an uncommon event which therefore particularly marks an individual out as being at higher fracture risk than their peers (i.e., relative to the background population risk). This is consistent with the lower absolute incidences of second fracture in these groups compared with those in
Table 2 Average incidence per 10,000 person-years of subsequent fracture from 1990 to 2012 in women aged $50+$ years

\begin{tabular}{lllllll}
\hline \multicolumn{7}{l}{ Subsequent fracture } \\
\cline { 2 - 6 } Index fracture & Hip/femur & Vertebra & Humerus & Radius/ulna & Pelvis & Rib \\
\hline Hip/femur & & 44.5 & 88.2 & 117.2 & 62.2 & 19.1 \\
Vertebra & 154.8 & & 71.8 & 93.4 & 58.6 & 37.9 \\
Humerus & 116.5 & 36.3 & & 154.9 & 29.5 & 16.0 \\
Radius/ulna & 82.4 & 27.4 & 80.1 & & 19.4 & 14.9 \\
Pelvis & 264.3 & 74.4 & 107.3 & 144.9 & & 32.1 \\
Rib & 87.2 & 55.2 & 63.0 & 96.5 & 26.7 & a \\
\hline
\end{tabular}

${ }^{\mathrm{a}}$ The number of fractures was too few to calculate meaningful incidence rates 
Table 3 Incidence of subsequent fractures per 10,000 py after a hip/ femur fracture in persons aged $50+$, by 5 -year age class in the UK from 1990 to 2012

\begin{tabular}{|c|c|c|c|c|c|c|}
\hline \multirow[b]{3}{*}{ Age (years) } & \multicolumn{6}{|c|}{ Subsequent fracture site } \\
\hline & \multicolumn{2}{|c|}{ Vertebra } & \multicolumn{2}{|c|}{ Humerus } & \multicolumn{2}{|c|}{ Radius/ulna } \\
\hline & M & $\mathrm{F}$ & M & $\mathrm{F}$ & M & $\mathrm{F}$ \\
\hline $50-54$ & 14.5 & 24.1 & 50.9 & 106.6 & 43.5 & 48.5 \\
\hline $55-59$ & 21.4 & 16.0 & 75.8 & 68.6 & 76.3 & 97.5 \\
\hline $60-64$ & 56.1 & 32.7 & 44.5 & 61.8 & 36.3 & 90.8 \\
\hline $65-69$ & 29.2 & 37.8 & 52.2 & 90.5 & 39.1 & 89.3 \\
\hline $70-74$ & 25.6 & 49.8 & 59.2 & 97.4 & 33.4 & 142.6 \\
\hline $75-79$ & 39.9 & 50.4 & 59.2 & 85.4 & 26.7 & 129.3 \\
\hline $80-84$ & 51.6 & 53.8 & 55.1 & 87.1 & 28.3 & 129.6 \\
\hline $85-89$ & 55.0 & 43.0 & 57.2 & 87.6 & 33.4 & 115.9 \\
\hline $90+$ & 34.6 & 37.0 & 69.3 & 94.0 & 58.9 & 101.1 \\
\hline
\end{tabular}

$M$ males, $F$ females

women and at older ages; in these latter situations, the background population risk is higher and the occurrence of a fracture is likely to have less of a relative impact on future fracture risk. The increase with age in the incidence of pelvis, vertebra, and hip fractures following an index fracture is consistent with the known epidemiology of these fractures, and that changes in neuromuscular ability with age, for example, the tendency to fall backward or sideways rather than forwards, lead to particular increases in these fracture types compared with those of the upper limb. The younger average age of radius/ ulna fractures as the index fracture will permit this age-related pattern to be more visible compared with hip as the index fracture (which tend to occur at older ages).

Table 4 Relative risk of subsequent fractures after hip/femur fracture in persons aged 50+, by 5-year age class, in the UK from 1990 to 2012

\begin{tabular}{|c|c|c|c|c|c|c|}
\hline \multirow[b]{3}{*}{ Age (years) } & \multicolumn{6}{|c|}{ Subsequent fracture site } \\
\hline & \multicolumn{2}{|c|}{ Vertebra } & \multicolumn{2}{|c|}{ Humerus } & \multicolumn{2}{|c|}{ Radius/ulna } \\
\hline & $\mathrm{M}$ & $\mathrm{F}$ & M & $\mathrm{F}$ & $\mathrm{M}$ & $\mathrm{F}$ \\
\hline $50-54$ & 6.9 & 11.5 & 8.5 & 14.2 & 8.3 & 3.7 \\
\hline $55-59$ & 9.3 & 6.1 & 12.9 & 7.1 & 9.4 & 5.5 \\
\hline $60-64$ & 17.5 & 8.8 & 7.2 & 5.6 & 4.5 & 4.3 \\
\hline $65-69$ & 7.9 & 7.0 & 7.6 & 6.9 & 5.0 & 3.6 \\
\hline $70-74$ & 5.0 & 6.0 & 7.6 & 5.8 & 4.0 & 5.0 \\
\hline $75-79$ & 5.1 & 3.9 & 5.9 & 3.9 & 2.6 & 3.6 \\
\hline $80-84$ & 4.6 & 2.9 & 3.8 & 3.0 & 2.4 & 3.0 \\
\hline $85-89$ & 3.3 & 1.9 & 2.7 & 2.3 & 2.0 & 2.3 \\
\hline $90+$ & 1.8 & 1.6 & 2.8 & 2.2 & 3.1 & 1.8 \\
\hline
\end{tabular}

$M$ males, $F$ females
Two previous meta-analyses have given rather lower RR for subsequent fractures: In the first [6], the RR of a subsequent fracture (any, hip, vertebral, or wrist) was 2.4 for those with a prior hip fracture and approximately 2 for the other types of prior fractures. In a meta-analysis from 2004 [5], the RR of a subsequent fracture in men and women combined ranged from 1.8 to 2 . In a recent study from Denmark [16] examining subsequent fracture rates by observing a cohort of patients aged 50 years or older from 2001 to 2011, patients suffering an index fracture (especially a hip fracture) had a high incidence of subsequent fractures. Depending on the type of initial fracture, the risk of a subsequent fracture within the following 10 years in men ranged from 5 to $15 \%$ for forearm fractures, $8-24 \%$ for humerus fractures, and $9-34 \%$ for hip fractures. For women, the equivalent rates were 11-25, 9-27, and $13-40 \%$, respectively. In a recent international, questionnaire-based study in women of 55 years or older and with a follow-up of 2 years [17], the authors found that the risk of a subsequent fracture increased with the number of prior fractures. The RR of any fracture was 1.8 in women with one prior fracture increasing to 3 in those with two prior fractures and to 4.8 in women with more than two prior fractures. The varied RR across studies can be explained, at least to some extent, by the difference in studied populations, differences in fracture outcomes (for example, we studied hip/femur rather than hip alone), and other methodologies used. Because of the long period we studied, coinciding with the introduction of several effective antiosteoporosis medications and improvements in primary and secondary prevention, we considered the possibility that subsequent fracture risk has changed during the studied 22-year period. The reduction in subsequent rib fractures in women in the later compared with earlier period corresponds well with the reduction in rib fracture incidence from 1990 to 2012 we observed in an earlier study [21]. This may reflect a reduction reporting of rib fractures as a result of changes to clinical assessment rather than a true secular change in incidence [21], but with this as with the other potential secular differences we observed, other changes such as alterations to the age and ethnicity distribution of the cohort over time will also have made contributions.

In the meta-analysis from 2004 [5], correction for BMD only lowered the risk of subsequent fractures by approximately $10 \%$, emphasizing the importance of prior fractures with regard to future fracture risk, and showing that this risk is to some extent independent of BMD. In a study from Canada from 2009 [18], the RR for low-trauma fracture in persons 50 90 years of age with a prior fracture was 14.6 in men with osteoporosis and 9.2 in women with osteoporosis. In men and women with osteopenia, this was 4.1 and 5.5, respectively, and in the group of individuals with a normal BMD, men had a RR of 6.4 , while the RR in women was not statistically significantly raised. The authors found that subsequent clinically symptomatic low-trauma fractures constitute one quarter 
of the overall fracture burden in men and just under one half of the fracture burden in women [18]. Conversely, in a recent study from Australia [19], the RR of subsequent fracture was $>2.0$-fold for all levels of BMD, demonstrating the high burden of subsequent fracture across all levels of BMD score.

Our study has some limitations that should be considered in the interpretation of our results. Firstly, although in general, fractures recorded in CPRD have been shown to be reliably coded [28], it is nevertheless possible that some fractures may have been misclassified as soft tissue injuries or incorrectly coded. In common with many other primary care databases, it is possible that fractures treated purely on an outpatient basis may have been less reliably captured than those necessitating hospital admission, most likely leading to an underestimate of incidence rates overall. Secondly, it is well-established that vertebral fractures are underdiagnosed [32], and this means that the incidences of subsequent vertebral fractures we found are also probably underestimated. Thirdly, owing to the difficulty in distinguishing two separate fractures of the same site that occur close in time, from a second reporting of the first fracture, we did not include subsequent fractures at the same individual site, which is likely to have resulted in an underestimate of fracture incidence, especially because subsequent fractures at the same anatomical (ipsilateral or contralateral) site have a relative high incidence $[15,33]$. This limitation will probably particularly affect the detection of multiple vertebral fractures. Furthermore, we were not able to explore the timecourse of the risk relationship, as has been undertaken elsewhere [34]. Fourthly, because of the extremely large number of individuals in the dataset, it was not possible to readily calculate incidences on the basis of exact dates of fracture and time at risk. Although this will have led to some minor loss of resolution in the results, this factor is unlikely to have systematically changed our findings overall. Fifthly, due to inherent limitations of our database, we were not able to provide information with regard to the duration of the time to a subsequent fracture. Sixthly, CPRD covers $7 \%$ of the UK population [25] and therefore may not fully represent fracture rates in all areas of the UK. However, the dataset has been shown to be generally representative of the UK population [25]. Additionally, we were not able to investigate whether fracture risks might have changed in the years subsequent to 2012. Finally, we did not take competing mortality risks into account, which can potentially cause an underestimation of the probability (accounting for death risk) of subsequent fractures, especially after hip and vertebral fractures $[35,36]$, and potentially differential by sex, since death rates differ between men and women. Importantly, the figures we report document the fractures that actually happened, rather than the theoretical incidence that might occur after accounting for death rates and thus are likely to be the appropriate metric to inform approaches to risk assessment.

In conclusion, we have demonstrated in the UK CPRD that an index fracture is associated with a markedly raised risk of subsequent fractures, with, for example, a relative risk of subsequent fractures after an index hip fracture between 2 and 7 compared with the risk of a first fracture at these sites. Our findings strongly support the need for prompt appropriate assessment and treatment to reduce risk of future fractures, following an index event in persons aged $50+$ years and that resource is urgently needed to close the current care gap experienced by many patients with osteoporosis worldwide.

Funding information TvS and $\mathrm{NCH}$ are joint senior author. The work was supported by a grant from the National Osteoporosis Society. This work was further supported by the Medical Research Council, British Heart Foundation, Arthritis Research UK, International Osteoporosis Foundation, National Institute for Health Research (NIHR) Southampton Biomedical Research Centre, University of Southampton and University Hospital Southampton NHS Foundation Trust, and NIHR Oxford Biomedical Research Centre, University of Oxford.

\section{Compliance with ethical standards}

Conflicts of interest None.

\section{References}

1. McClung MR, Geusens PPMM, Miller PD et al (2001) Effect of risedronate on the risk of hip fracture in elderly women. $\mathrm{N}$ Engl $\mathrm{J}$ Med 344:333-340

2. Marshall D, Johnell O, Wedel H (1996) Meta-analysis of how well measures of bone density predict occurrence of osteoporotic fractures. BMJ 312:1254-1259

3. Turner DA, Khioe RFS, Shepstone L, Lenaghan E, Cooper C, Gittoes N, Harvey NC, Holland R, Howe A, McCloskey E, O'Neill TW, Torgerson D, Fordham R, SCOOP Study Team (2018) The cost-effectiveness of screening in the community to reduce osteoporotic fractures in older women in the UK: economic evaluation of the SCOOP study. J Bone Miner Res 33(5):845-851

4. Pasco JA, Seeman E, Henry MJ, Merriman EN, Nicholson GC, Kotowicz MA (2006) The population burden of fractures originates in women with osteopenia, not osteoporosis. Osteoporos Int 17(9): 1404-1409

5. Kanis JA, Johnell O, De Laet C et al (2004) A meta-analysis of previous fracture and subsequent fracture risk. Bone 35(2):375-382

6. Klotzbuecher CM, Ross Ph D, Landsman PB et al (2000) Patients with prior fractures have an increased risk of future fractures: a summary of the literature and statistical synthesis. JBMR 15(4): 721-739

7. Porthouse J, Birks YF, Torgerson DJ, Cockayne S, Puffer S, Watt I (2004) Risk factors for fracture in a UK population: a prospective cohort study. QJM 97:569-574

8. Gehlbach S, Saag K, Flahive J et al (2010) GLOW investigators: previous fractures increase risk for subsequent fractures at multiple sites: global longitudinal study of osteoporosis in women. Bone 47: S180

9. Huntjens KMB, Kosar S, van Geel TACM, Geussens PP, Willems P, Kessels A, Winkens B, Brink P, van Helden S (2010) Risk of subsequent fracture and mortality within 5 years after a nonvertebral fracture. Osteoporos Int 21(12):2075-2082

10. NICE (2008) Alendronate, etidronate, risedronate, raloxifene, strontium ranelate and teriparatide for the secondary prevention of osteoporotic fragility fractures in postmenopausal women. NICE technology appraisal guidance 161 
11. Compston J, Cooper A, Cooper C, Gittoes N, Gregson C, Harvey N, Hope S, Kanis JA, McCloskey EV, Poole KES, Reid DM, Selby P, Thompson F, Thurston A, Vine N, National Osteoporosis Guideline Group (NOGG) (2017) UK clinical guideline for the prevention and treatment of osteoporosis. Arch Osteoporos 12(1):43

12. Harvey NC, McCloskey EV, Mitchell PJ, Dawson-Hughes B, Pierroz DD, Reginster JY, Rizzoli R, Cooper C, Kanis JA (2017) Mind the (treatment) gap: a global perspective on current and future strategies for prevention of fragility fractures. Osteoporos Int 28(5): $1507-1529$

13. Papaioannou A, Kennedy CC, Ioannidis G, Gao Y, Sawka AM, Goltzman D, Tenenhouse A, Pickard L, Olszynski WP, Davison KS, Kaiser S, Josse RG, Kreiger N, Hanley DA, Prior JC, Brown JP, Anastassiades T, Adachi JD, CaMos Research Group (2008) The osteoporosis care gap in men with fragility fractures: the Canadian multicentre osteoporosis study. Osteoporos Int 19(4):581-587

14. de Laet CEDH, van der Klift M, Hofman A, Pols HAP (2002) Osteoporosis in men and women: a story about bone mineral density thresholds and hip fracture risk. J Bone Miner Res 17:2231-2236

15. van Staa TP, Leufkens, Cooper C (2002) Does a fracture at one site predict later fractures at other sites? A Britisch cohort study. Osteoporos Int 13(8):624-629

16. Hansen L, Petersen KD, Eriksen SA, Langdahl BL, Eiken PA, Brixen K, Abrahamsen B, Jensen J-EB, Harslof T, Vestergaard P (2015) Subsequent fracture rates in a nationwide population-based cohort study with a 10-year perspective. Osteoporos Int 26(2):513-519

17. Gehlbach S, Saag KG, Adachi JD, Hooven FH, Flahive J, Boonen S, Chapurlat RD, Compston JE, Cooper C, Díez-Perez A, Greenspan SL, LaCroix AZ, Netelenbos JC, Pfeilschifter J, Rossini M, Roux C, Sambrook PN, Silverman S, Siris ES, Watts NB, Lindsay R (2012) Previous fractures at multiple sites increase the risk for subsequent fractures: the global longitudinal study of osteoporopsis in women. J Bone Miner Res 27(3):645-653

18. Langsetmo L, Goltzman D, Kovacs CS, Adachi JD, Hanley DA, Kreiger N, Josse R, Papaioannou A, Olszynski WP, Jamal SA, the CaMos Research Group (2009) Repeat low-trauma fractures occur frequently among men and women who have osteopenic BMD. J Bone Miner Res 24(9):1515-1522

19. Bliuc D, Alarkawi D, Nguyen TV, Eisman JA, Center JR (2015) Risk of subsequent fractures and mortality in elderly women and men with fragility fractures with and without osteoporotic bone density: the Dubbo osteoporosis epidemiology study. J Bone Miner Res 30(4):637-646

20. Gibson-Smith D, Klop C, Elders PJM, Welsing PMJ, van Schoor N, Leufkens HGM, Harvey NC, van Staa TP, de Vries F (2014) The risk of major and any (non-hip) fragility fracture after hip fracture in the UK: 2000-2010. Osteoporos Int 25:2555-2563

21. van der Velde RY, Wyers CE, Curtis EM, Geussens PPMM, van den Bergh JPW, de Vries F, Cooper C, van Staa TP, Harvey NC (2016) Secular trends in fracture incidence in the UK between 1990 and 2012. Osteoporos Int 27(11):3197-3206. https://doi.org/10. 1007/s00198-016-3650-3

22. Curtis EM, van der Velde RY, Moon RJ, van den Bergh JPW, Geusens PPMM, de Vries F, van Staa TP, Cooper C, Harvey NC
(2016) Epidemiology of fractures in the United Kingdom 19882012: variation with age, geography, ethnicity and socioeconomic status. Bone 87:19-26

23. Williams T, van Staa T, Puri S, Eaton S (2012) Recent advances in the utility and use of the general practice research database as an example of a UK primary care data resource. Ther Adv Drug Saf 3(2):89-99. https://doi.org/10.1177/2042098611435911

24. Walley T, Mantgani A (1997) The UK General Practice Research Database. Lancet 350(9084):1097-1099. https://doi.org/10.1016/ s0140-6736(97)04248-7

25. Herrett E, Gallagher AM, Bhaskaran K, Forbes H, Mathur R, van Staa T, Smeeth L (2015) Data resource profile: clinical practice research datalink (CPRD). Int J Epidemiol 44(3):827-836. https:// doi.org/10.1093/ije/dyvD98

26. Mathur R, Bhaskaran K, Chaturvedi N, Leon DA, vanStaa T, Grundy E, Smeeth L (2014) Completeness and usability of ethnicity data in UK-based primary care and hospital databases. J Public Health (Oxf) 36(4):684-692

27. Chisholm J (1990) The read clinical classification. BMJ 300:1092

28. Van Staa TP, Abenhaim L, Cooper C, Zhang B, Leufkens HG (2000) The use of a large pharmacoepidemiological database to study exposure to oral corticosteroids and risk of fractures: validation of study population and results. Pharmacoepidemiol Drug Saf 9:359-366. https://doi.org/10.1002/1099-1557(200009/10)9: 5<359::AID-PDS507>3.0.C0;2-E

29. Khan NF, Harrison SE, Rose PW (2010) Validity of diagnostic coding within the general practice research database: a systematic review. Br J Gen Pract 60(572):e128-e136. https://doi.org/10.3399/ bjgp10X483562

30. Herrett EL, Thomas SL, Smeeth L (2011) Validity of diagnoses in the general practice research database. Br J Gen Pract 61(588):438 439. https://doi.org/10.3399/bjgp11X583092

31. Johnell O, Oden A, Coulin F, Kanis JA (2001) Acute and long-term increase in fracture risk after hospitalization for vertebral fracture. Osteoporos Int 12(3):207-214

32. Delmas PD, van de Langerijt L, Watts NB, Eastell R, Genant H, Grauer A, Cahall DL, IMPACT Study Group (2005) Underdiagnosis of vertebral fractures is a worldwide problem: the IMPACT study. J Bone Miner Res 20(4):557-563

33. Ryg J, Rejnmark L, Overgaard S, Brixen K, Vestergaard P (2009) Hip fracture patients at risk of second hip fracture: a nationwide population-based cohort study of 169,145 cases during 1977-2001. J Bone Miner Res 24:1299-1307

34. Johansson H, Siggeirsdóttir K, Harvey NC, Odén A, Gudnason V, McCloskey E, Sigurdsson G, Kanis JA (2017) Imminent risk of fracture after fracture. Osteoporos Int 28(3):775-780

35. Sernbo I, Johnell O (1993) Consequences of a hip fracture: a prospective study over 1 year. Osteoporos Int 3(3):148-153

36. Curtis JR, Arora T, Matthews RS, Taylor A, Becker DJ, ColonEmeric C, Kilgore ML, Morrisey MA, Saag KG, Safford MM, Warriner A, Delzell F (2010) Is withholding osteoporosis medication after fracture sometimes rational? A comparison of the risk for second fracture versus death. J Am Med Dir Assoc 11:584-591 